\title{
MicroRNAs and Exosomal microRNAs May Be Possible Targets to Investigate in Gestational Diabetes Mellitus
}

\author{
Xiyao Yang', $\mathrm{Na} \mathrm{Wu}{ }^{1,2}$ \\ 'Department of Endocrinology, Shengjing Hospital of China Medical University, Shenyang, People's Republic of China; ${ }^{2}$ Clinical Skills Practice Teaching \\ Center, Shengjing Hospital of China Medical University, Shenyang, People's Republic of China \\ Correspondence: Na Wu, Department of Endocrinology, Shengjing Hospital of China Medical University, 36 Sanhao Road, Heping District, Shenyang, \\ Liaoning Province, I 10004, People's Republic of China, Tel +86 I8940258445, Email 344I535223@qq.com
}

\begin{abstract}
Gestational diabetes mellitus (GDM) is defined as glucose intolerance that occurs during the second or third trimester of pregnancy. As the incidence of GDM rises, so does the risk of maternal and fetal complications with short- and long-term consequences. As a result, early diagnosis and treatment of this condition are important to avoiding adverse pregnancy outcomes. Exosomes are tiny vesicles secreted by living cells which contain a variety of bioactive substances. They are released by cells to facilitate cell-to-cell communication and regulate a variety of biological processes such as cellular immune response, inflammatory response, and apoptosis, among others. Many studies have recently confirmed that changes in the expression and secretion of exosomal miRNAs can be used as novel markers for the diagnosis, prognosis, and treatment of GDM. In this review, we summarized the various roles of exosomal miRNAs and circulating miRNAs in GDM. We found that the changes in the expression of certain miRNAs could be used to diagnosing GDM. Exosomal miRNAs target metabolic pathways, resulting in insulin resistance. We also highlighted the potential for miRNAs and exosomal miRNAs to be used as biomarkers for diagnosis or therapeutic agents.
\end{abstract}

Keywords: GDM, exosomal miRNA, biomarker, insulin resistance, pregnancy

\section{Introduction}

Gestational diabetes mellitus (GDM) is glucose intolerance diagnosed for the first time during pregnancy. ${ }^{1}$ It occurs when the pancreatic $\beta$-cell function is unable to overcome insulin resistance (IR). According to the International Diabetes Federation, GDM occurred in approximately $14 \%$ and $21 \%$ of the world and Asian populations, respectively, in $2017 .^{2}$ In recent years, the global prevalence of GDM has increased. Without proper diagnosis and treatment, GDM can lead to adverse pregnancy outcomes for both the mother and unborn child, including shortterm adverse outcomes such as hypoxia, foetal death, hypoglycemia, and respiratory distress syndrome. In particular, children born to mothers with GDM are at an increased risk of developing metabolic and cerebrovascular disease in adulthood. Women with GDM are also at an increased risk of developing pregnancy-induced hypertension, preeclampsia and common delivery complications. ${ }^{3,4}$ As a result, screening for abnormal blood glucose levels is generally recommended as a routine check-up for pregnant women, but common screening diagnoses are frequently made in the second and third trimesters of pregnancy. Improved screening strategies, early diagnosis, and early treatment are required to ensure maternal and fetal health. Recently, many researchers are studying potential biomarkers in the blood to diagnose GDM before 24-28 weeks of gestation. ${ }^{5}$ Exosomal microRNAs (miRNAs) have shown considerable potential as early-trimester biomarkers for GDM due to their high stability in body fluids and accessibility from maternal fluids throughout gestation. ${ }^{6}$

MicroRNAs are a kind of endogenous non-coding single-stranded RNA which are about 22 nucleotides in length and participate in the regulation of post-transcriptional gene expression secreted by blasts cells and found in many biological 
fluids, ${ }^{7}$ such as serum and plasma. This property makes miRNAs the optimum biomarker or sensor for detecting in situ tissue changes.

Exosomes are nanoscale extracellular vesicles $(40-120 \mathrm{~nm})$ released from many cell types, ${ }^{8}$ and found in a variety of natural body fluids such as peripheral blood, urine, breast milk, and amniotic fluid. Exosomes contain a large number of proteins, long non-coding RNA (lncRNA), miRNA, and other bioactive substances which are released by cells to facilitate cell-to-cell communication. They participate in several biological processes by regulating various physiological and pathological functions of the recipient cells, such as cellular immune response, inflammatory response, and apoptosis, as well as guiding tumor cells growth and development. ${ }^{9}$ Exosome concentrations in the peripheral blood of pregnant women with GDM were significantly higher than those of non-GDM pregnant women. Importantly, age and pregnancy status have been confirmed as important factors that contribute to changes in plasma exosome concentrations. Although both of the exosomal consistency and concentration increase during normal and GDM pregnancies, exosomal concentration is higher in GDM pregnancy than in normal pregnancy. ${ }^{10,11}$ Furthermore, miRNAs secreted by exosomes contribute to tissue information transmission; thus, if miRNA secretion transmission is interrupted, it may cause tissue/ cell dysfunction in a specific disease (e.g. GDM). ${ }^{12,}$

All in all, exosomal miRNAs secreted by tissues, as exosome bioactive substances, may lead to the occurrence of GDM. Changes in the expression of some exosomal miRNAs can promote the occurrence of complications; thus, miRNAs can play a vital role in the early diagnosis, clinical treatment, and prognosis of diseases. We summarize the pathophysiological significance of circulating miRNAs in the development of GDM, and their potential role in clinical diagnosis and treatment of GDM. Additionally, we discussed the role of exosomal miRNAs in the postpartum outcome of GDM, and the potential functions of several miRNAs and exosomal miRNAs as therapeutic targets in the pathological pathway of GDM, thus providing new clinical insights on these biological characteristics for the treatment of GDM. In the future, we believe that GDM will be treated and prevented by regulating the expression of exosomal miRNAs, thereby reducing the adverse effects of GDM and its complications in both mother and child.

\section{miRNAs and GDM Pathophysiology}

\section{Pathogenesis of GDM}

The pathophysiological characteristics of GDM mainly include maternal IR, placental dysfunction, $\beta$-cell dysfunction and inflammation, ${ }^{13}$, but the molecular mechanisms involved in its development have not been fully elucidated. To ensure an adequate nutritional supply to the fetus, increased secretion of placental hormones is required, which leads to a physiological increase in IR in the mid-late gestation. ${ }^{14}$ Pancreatic $\beta$-cell proliferation is a normal pregnancy phenomenon which leads to high fasting and postprandial blood glucose levels. Under normal circumstances, insulin compensatory secretion could preserve glucose homeostasis. However, if $\beta$-cell dysfunction occurs, the compensation effect is lost, and hyperglycemia during pregnancy becomes notable. Inadequate adaptation of $\beta$-cells to peripheral IR may be the main pathophysiological mechanism underlying GDM-associated glucose intolerance and hyperglycemia. ${ }^{15}$

\section{Differentially Expressed Circulating miRNAs in Patients with GDM and Control Subjects}

Recently, many studies have shown changes in the expression and metabolism of miRNAs in GDM (see Table 1).

Seven studies found that the expressions of miRNA was lower in GDM patients compared with normal pregnant women. A control case revealed that, the expression of miR-132 in serum and placenta of GDM patients decreased. Serum miR-132 level of GDM patients is negatively correlated with fasting blood glucose. High glucose (HG) treatment induced the proliferation HTR-8/SVneo cells while inhibiting miR-132 expression. Overexpression of miR-132 in HTR-8/SVneo cells could significantly save the inhibited cell proliferation induced by HG. ${ }^{16}$ Another study shows that compared with control group with similar gestational weeks, the expression levels of three miRANs (miR-132, miR-29a, and miR-222) in GDM women were significantly lower. Furthermore, miR-29a knockout can increase insulin-induced gene 1 (Insig1) expression level in HepG2 cell line, which then increase phosphoenolpyruvate carboxykinase 2 (PCK2) level. ${ }^{17}$ Other studies found that the content of MiR-20a-5p and miR-222-3p in women with GDM decreased by 2.7 and 2.6 times, 
Table I Biological Functions of GDM-Related Circulating miRNAs

\begin{tabular}{|c|c|c|c|c|c|c|c|}
\hline Study & $\begin{array}{l}\text { Groups/ } \\
\text { Number }\end{array}$ & $\begin{array}{l}\text { Stage of } \\
\text { Pregnancy } \\
\text { (weeks) }\end{array}$ & miRNA & $\begin{array}{l}\text { Target } \\
\text { Pathway }\end{array}$ & Species & Source & Role/Biological Function \\
\hline \multirow{2}{*}{$\begin{array}{l}\text { Xuegui } \\
\text { Zhou }^{16}\end{array}$} & 108 GDM & \multirow[t]{2}{*}{$24-28$} & \multirow[t]{2}{*}{ miR-I32 } & \multirow{2}{*}{$\begin{array}{l}\text { HTR-8/SVneo } \\
\text { cells }\end{array}$} & \multirow[t]{2}{*}{ Human } & \multirow{2}{*}{$\begin{array}{l}\text { Serum } \\
\text { and } \\
\text { placenta }\end{array}$} & \multirow{2}{*}{$\begin{array}{l}\text { Promote the trophoblast cell } \\
\text { proliferation }\end{array}$} \\
\hline & $50 \mathrm{CTRL}$ & & & & & & \\
\hline \multirow{2}{*}{$\begin{array}{l}\text { Chun } \\
\text { Zhao }\end{array}$} & 32 GDM & \multirow[t]{2}{*}{$16-19$} & \multirow{2}{*}{$\begin{array}{l}\text { miR-132, } \\
\text { miR-29a and } \\
\text { miR-222 }\end{array}$} & \multirow{2}{*}{$\begin{array}{l}\text { PCK2 in HepG2 } \\
\text { cell lines. }\end{array}$} & \multirow[t]{2}{*}{ Human } & \multirow[t]{2}{*}{ Serum } & \multirow[t]{2}{*}{ Decrease Insulin-induced gene I (Insig I) } \\
\hline & 32 CTRL & & & & & & \\
\hline $\begin{array}{l}\text { Carmen } \\
\text { Pheiffer }^{18}\end{array}$ & 81 & $|3-3|$ & $\begin{array}{l}\text { miR-20a-5p, } \\
\text { miR-222-3p }\end{array}$ & - & Human & Serum & $\begin{array}{l}\text { Various metabolic pathways, including } \\
\text { insulin signaling. }\end{array}$ \\
\hline $\begin{array}{l}\text { Shuping } \\
\mathrm{Qi}^{19}\end{array}$ & 156 & $24-28$ & $\operatorname{miR}-185$ & - & Human & $\begin{array}{l}\text { Serum } \\
\text { and } \\
\text { placental }\end{array}$ & Increase FPG, FINS, and HOMA-IR \\
\hline \multirow{2}{*}{$\begin{array}{l}\text { Chun-Yi } \\
\text { Guan }^{20}\end{array}$} & I37GDM & \multirow[t]{2}{*}{$24-28$} & \multirow[t]{2}{*}{ miR-2I-5p } & \multirow[t]{2}{*}{ PPAR- $\alpha$} & \multirow[t]{2}{*}{ Human } & \multirow[t]{2}{*}{ Serum } & \multirow{2}{*}{$\begin{array}{l}\text { Inhibits cell growth and infiltration, } \\
\text { affect the placental function. }\end{array}$} \\
\hline & I58CTRL & & & & & & \\
\hline \multirow[t]{2}{*}{ Li Deng ${ }^{21}$} & 68GDM & \multirow[t]{2}{*}{$24-28$} & \multirow[t]{2}{*}{$\mathrm{miR}-29 \mathrm{a} / \mathrm{b}$} & \multirow[t]{2}{*}{ - } & \multirow[t]{2}{*}{ Human } & \multirow[t]{2}{*}{ Serum } & \multirow[t]{2}{*}{ Neonatal pathologic jaundice } \\
\hline & 55CTRL & & & & & & \\
\hline \multirow{2}{*}{$\begin{array}{l}\text { Songbo } \\
\mathrm{Fu}^{22}\end{array}$} & 90 GDM & \multirow[t]{2}{*}{-} & \multirow[t]{2}{*}{ miR-875-5p } & \multirow[t]{2}{*}{ TXNRDI } & Rat & Serum & Reduced FBG and insulin resistance, \\
\hline & IOCTRL & & & & & & $\begin{array}{l}\text { reduced expression levels of blood lipid } \\
\text { and pro-inflammatory markers as well as } \\
\text { reduced oxidative stress }\end{array}$ \\
\hline Guido & 21 GDM & $24-33$ & miR-330-3p & Directly be & Human & Plasma & Modulating key target genes involved in \\
\hline Sebastiani $^{23}$ & I0 CTRL & & & $\begin{array}{l}\text { transferred from } \\
\text { plasma to beta- } \\
\text { cells }\end{array}$ & & & $\begin{array}{l}\text { proliferation, differentiation, and insulin } \\
\text { secretion. }\end{array}$ \\
\hline Jianping & 102 GDM & $24-28$ & miR-195-5p & - & Human & Serum & Fasting plasma glucose, one-hour plasma \\
\hline Wang ${ }^{2-}$ & I02 CRTL & & & & & & $\begin{array}{l}\text { glucose, two-hour plasma glucose, and } \\
\text { BMI }\end{array}$ \\
\hline Sujuan & 67GDM & $24-28$ & $\operatorname{miR}-2467$ & Adiponectin & Human & Serum & Increase (BMI), TC, TG, LDL-C, FPG, \\
\hline $\mathrm{Dai}^{2}$ & $60 \mathrm{CTRL}$ & & & & & & HbAlc, HOMA-IR \\
\hline Anja Elaine & 82GDM & $<20,24$ & miR-16-5p, & - & Human & Serum & Increase the incident of macrosomia \\
\hline Sørensen ${ }^{26}$ & 4ICRTL & $28,35-37$ & $\begin{array}{l}-29 a-3 p \\
\text { and }-134-5 p\end{array}$ & & & & \\
\hline Lijun $\mathrm{Liu}^{27}$ & 110 GDM & $24-28$ & miR-I 323 & TP53INPI & Human & Blood & Promote the trophoblast cell viability \\
\hline & 78CTRL & & & & & & under HG conditions \\
\hline Hui Shen ${ }^{28}$ & 25GDM & $20-24$ & miR-I8Id & IRS-2 & Human & Serum & Modulated the process of insulin \\
\hline & $30 C T R L$ & & & & & & $\begin{array}{l}\text { signaling and cell viability and apoptosis } \\
\text { in pancreatic } \beta \text { cells }\end{array}$ \\
\hline Jie $\mathrm{Wen}^{29}$ & 32 GDM & $25-31$ & miR-520h & mTOR & Human & Serum & Inhibit cell viability and promote cell \\
\hline & 48CTRL & & & & & & apoptosis \\
\hline
\end{tabular}


Table I (Continued).

\begin{tabular}{|l|l|l|l|l|l|l|l|}
\hline Study & $\begin{array}{l}\text { Groups/ } \\
\text { Number }\end{array}$ & $\begin{array}{l}\text { Stage of } \\
\text { Pregnancy } \\
\text { (weeks) }\end{array}$ & miRNA & $\begin{array}{l}\text { Target } \\
\text { Pathway }\end{array}$ & Species & Source & Role/Biological Function \\
\hline $\begin{array}{l}\text { Fuyan } \\
\text { Wang }\end{array}$ & 53 GDM & $24-28$ & $\begin{array}{l}\text { miR-574-5p } \\
\text { and miR- } \\
3135 b\end{array}$ & $\begin{array}{l}\text { The metabolism } \\
\text { of glucose and } \\
\text { lipids, the insulin } \\
\text { signaling pathway }\end{array}$ & Human & Plasma & $\begin{array}{l}\text { Levels of blood glucose and LDL-C; } \\
\text { HDL-C }\end{array}$ \\
\cline { 2 - 7 } & TaCTRL \\
Zheng
\end{tabular}

Abbreviations: CTRL, control; GDM, gestational diabetes mellitus; TXNRDI, thioredoxin reductase I; PCK2, phosphoenolpyruvate carboxy kinase2; TP53INPI, tumor protein p53 inducible nuclear protein I; miRNA, microRNA; PPAR $\alpha$, peroxisome proliferator-activated receptor $\alpha$.

respectively. ${ }^{18}$ When compared with non-GDM group, the level of miR-185 in serum and placenta in the severe GDM group was the lowest, while it was lower in the mild GDM group. In 156 patients with GDM, serum and placental miR-185 levels were negatively correlated with HOMA-IR, and GDM patients could be distinguished from the control group. ${ }^{19}$ In GDM patients, the expression of miR-21-5p in placenta is down-regulated, which may affect placental function further, and it inhibits cell growth and infiltration by up-regulating PPAR- $\alpha .{ }^{20}$ The expression of serum miR-29a/b is down-regulated in pregnant women with GDM disease, which is related to pathological newborn jaundice. ${ }^{21}$ Compared with normal pregnant rats, the expression of miR-875-5p in GDM rats was down-regulated, while a TXNRD1 expression was up-regulated. MiR8755p significantly regulated TXNRD1 expression in GDM rats. MiR-875-5p regulates iR and inflammation in GDM rats by targeting TXNRD $1 .{ }^{22}$

While eleven studies found an increase expression in miRNAs in the GDM group. One study found the up-regulation of miR-330-3p in plasma of GDM vs non-diabetic patients. MiR-330-3p may be helpful to identify GDM patients who may have a poor prognosis of gestational diabetes. In GDM, miR-330-3p can be directly transferred from plasma to $\beta$ cells, where it regulates key target genes involved in proliferation, differentiation, and insulin secretion. ${ }^{23}$ Another study found that the expression of miR-195-5p in serum of GDM patients is significantly increased. The expression of miR195-5p is positively correlated with fasting blood glucose, 1-hour blood glucose, 2-hour blood glucose, and BMI. ${ }^{24}$ Body mass index (BMI), TC, TG, LDL-C, FPG, HbA1c, HOMA-IR, and serum miR-2467 levels are higher in the GDM group than in the control group. Serum miR-2467 levels in GDM pregnant women were found to be positively correlated with them. Logistic regression analysis showed that serum miR-2467 level was an independent risk factor for GDM. A conserved binding site was found in the 3'UTR region of adiponectin, and the analysis of double luciferase reporter assay showed that adiponectin was a target gene of miR-2467. ${ }^{25}$ Compared with the control group remaining in NGT, the levels of miR-16-5p, -29a-3p and -134-5p were increased in women who developed into GDM. The combined application three miRNAs is more suitable than fasting blood glucose in distinguishing advanced GDM and NGT cases, and both miR-16-5p and miR-29a-3p are related to macrosomia. ${ }^{26}$ The up-regulated level of serum miR-1323 can be used as a diagnostic biomarker for GDM disease. Furthermore, under the condition of HG, knocking out miR-1323 in trophoblast cells may promote trophoblast cells survival by targeting TP53INP1. ${ }^{27}$ MiR-181d expression levels are positively correlated with fasting blood glucose levels. miR-181d regulates the insulin signal transduction process, and cell survival rate and apoptosis of pancreatic $\beta$ cells by targeting IRS-2, suggesting that miR-181d inhibition is a potential 
target for GDM therapy. ${ }^{28}$ miR-520h can inhibit cell survival and promote cell apoptosis by modulating mTOR expression. Therefore, miR-520h may be a potentially important marker for diagnosis and treatment of GDM disease. ${ }^{29}$ The expression of miR-574-5p was found to be significantly correlated to blood glucose and LDL-C levels. MiR-3135b has a significant correlation with HDL-C. Some of predicted target genes for these two miRNAs are associated in glucose and lipid metabolism, and the insulin signaling pathway. ${ }^{30}$ Resveratrol can improve the glucose uptake and lipid metabolism in IR GDM mice and adipocytes by regulating the miR-23a-3p/NOV axis. ${ }^{31}$ Another study observed that the levels of miR-9-5p, miR-29a-3p, and miR-330-3p in the serum of GDM patients were higher than in non-diabetic subjects, and that the correlation between urine level of some phthalates and miRNA expression level was related to GDM. ${ }^{32}$ One animal study discovered that miR-26b accelerates the process of gestational diabetes by inhibiting the PI3K/Akt signaling pathway. ${ }^{33}$

As previously demonstrated, miRNAs regulate $\beta$-cell mass and function as well as immune system homeostasis; they undoubtedly plays a major role in the pathogenesis of GDM, and there is a correlation between miRNA expression and GDM development.

\section{Role of Exosomal miRNAs on GDM Complications and Maternal and Infant Dysfunction}

The expression of 10 exosomal miRNAs in early (6-15 weeks of gestation) placental tissues collected from GDM patients is significantly higher than that in controls. These miRNAs are involved in trophoblast proliferation and differentiation in pregnant women, insulin secretion and regulation, and glucose transport, which may affect early placental development. ${ }^{34}$ The expression of miRNAs in fetal tissues exposed to intrauterine diabetes differed from the expression in fetal tissues of the unexposed offspring. Diabetes had a different effect on miRNA expression stratified by birth weight in the diabetes and control groups, with reduced placental expression of miR-126-3p at low birth weight but no difference at high birth weight. Moreover, GDM exposure decreased the expression of miR-148a-3p and miR-29a-3p in infant umbilical vein endothelial cells. Therefore, GDM exposure alters the expression of miRNAs in offspring in a tissue-specificity manner. What's more, miRNA expression varies by tissue type, and the response to diabetic exposure varies by tissue of origin. miRNA expression may be a potential mechanism through which maternal diabetes affects the future metabolic state of the offspring. ${ }^{35}$

GDM predisposes the mother and offspring to long-term complications in addition to increasing the risk of complications for both the mother and the fetus during pregnancy.

Despite the fact that more research is needed in this area, it gives us a new perspective on the possible causes of GDM complications.

\section{Exosomal miRNAs as Biomarkers for GDM Diagnosis}

Because exosomal miRNA secretion is associated with GDM, these molecules may be used as potential biomarkers for early GDM diagnosis because they have high stability in body fluids and easily obtained from pregnant women's blood throughout pregnancy (Table 2).

In total, 157 dysfunctional placental miRNAs were identified in a trial; in particular, miRNA-125b and miRNA-144 were always dysfunctional in the circulating exosomes and placenta of women with GDM, indicating their possible diagnostic value for GDM. miRNA-125b is downregulated, in GDM, whereas miRNA-144 is up-regulated, and miRNA144 concentration in the circulating exosomes are negatively related to body mass index before pregnancy and delivery and positively related to blood glucose at 1 hour. ${ }^{36}$ In another study, placental exosomes were extracted from the urine of pregnant women during the first, second, and third months of gestation; the levels of five miRNAs were measured, and they exhibited differential expression. In healthy pregnant women, all of them except miR-516-5p was not expressed in the second trimester of pregnancy. MiRNA expression increased throughout pregnancy, but in patients with GDM at three months of pregnancy, all examined miRNAs were downregulated, implying that, in addition to hematological testing, urinary exosomes can serve as an excellent source of biomarkers. ${ }^{37}$ In plasma samples, 44 miRNAs were upregulated in the exosomes of women with GDM compared to pregnant women with normal glucose tolerance (NGT). 
Table 2 Changes in the Expression of Exosomal miRNAs Related to Gestational Diabetes Mellitus (GDM)

\begin{tabular}{|c|c|c|c|c|c|}
\hline Study & Groups & $\begin{array}{l}\text { Stage of } \\
\text { Pregnancy }\end{array}$ & Species & Source & MiRNA \\
\hline \multirow[t]{2}{*}{ Lei Zhang ${ }^{36}$} & 57 GDM & $37-4 \mid$ weeks & \multirow[t]{2}{*}{ Human } & Placenta & \multirow{2}{*}{$\begin{array}{l}\operatorname{miRNA}-125 \mathrm{~b}(\downarrow) \\
\operatorname{miRNA}-144(\uparrow)\end{array}$} \\
\hline & 6I CTRL & $26-40$ weeks & & Plasma & \\
\hline \multirow{2}{*}{$\begin{array}{l}\text { Ana Sofía Herrera-Van } \\
\text { Oostdam }{ }^{37}\end{array}$} & 27 GDM & \multirow{2}{*}{$\begin{array}{l}\text { I-3 months after } \\
\text { delivery }\end{array}$} & \multirow[t]{2}{*}{ Human } & \multirow[t]{2}{*}{ Urine } & \multirow{2}{*}{$\begin{array}{l}\text { miR-516-5p, miR-517-3p, miR-5 18-5p, miR-222- } \\
\text { 3p, miR-16-5p }(\downarrow)\end{array}$} \\
\hline & 34 CTRL & & & & \\
\hline \multirow{2}{*}{$\begin{array}{l}\text { SOUMYALEKSHMI } \\
\text { NAIR }^{38}\end{array}$} & 12 GDM & \multirow[t]{2}{*}{ During delivery } & \multirow[t]{2}{*}{ Human } & \multirow[t]{2}{*}{ Plasma } & \multirow[t]{2}{*}{-} \\
\hline & 12 CTRL & & & & \\
\hline Zhenhong hang ${ }^{39}$ & 3000 & 24-28 weeks & Human & Plasma & miRI03-3p ( $\uparrow)$, miRNA-I48 family \\
\hline \multirow{2}{*}{$\begin{array}{l}\text { NANTHINI } \\
\text { JAYABALAN }^{40}\end{array}$} & 10 GDM & \multirow[t]{2}{*}{$>37$ weeks } & \multirow[t]{2}{*}{ Human } & \multirow{2}{*}{$\begin{array}{l}\text { Omental adipose } \\
\text { tissue }\end{array}$} & \multirow[t]{2}{*}{ Has-miR-5I5-5p ( $\uparrow)$} \\
\hline & $10 \mathrm{CTRL}$ & & & & \\
\hline
\end{tabular}

Abbreviation: CTRL, control.

Exosome miRNA isolated from GDM women regulated the expression of glycolytic pathway-related placental genes, including those encoding phosphofructokinase 6 and phosphopyruvate hydratase, according to IPA. Interestingly, exosome from women with GDM increases the expression of placental genes related to glycolysis and reduced the expression of genes related to glycolysis and the pentose phosphate pathway, respectively. This indicates that under diabetic conditions, circulating exosomes may regulate the placental metabolic state to enhance glycogen metabolism in GDM. ${ }^{38}$ According to studies, visceral fat thickness may cause IR by regulating the fat-derived exosome miRNA-148 family, leading in the development of GDM. ${ }^{39}$ Another study found that when compared to normal pregnancies, GDM pregnancies had an upregulation of 12 exosomal miRNAs and a downregulation of six miRNAs. Has-miR-515-5p was selected for further functional studies of these miRNAs. A quantitative reverse transcription polymerase chain reaction analysis of placental tissue showed that its expression was significantly higher in GDM placenta than in NGT placenta. Overexpression of mir-515-5p significantly increased glucose uptake in PHT cells. ${ }^{40}$

Presently, the oral glucose tolerance test (OGTT) using $75 \mathrm{~g}$ of glucose is used to screen and diagnose GDM by evaluating fasting 1-hour and 2-hour blood glucose levels during 24-28 weeks of gestation. ${ }^{41}$ The OGTT blood glucose threshold levels are 5.1, 10 and $8.5 \mathrm{mmol} / \mathrm{L}$, respectively. GDM can be diagnosed by using one or more values that exceed or equal these thresholds. ${ }^{42}$ Regrettably, treatment cannot begin in the first trimester of pregnancy, which increases the possibility of fetal incidence and mortality in the late stage. Therefore, early pregnancy screening is important in establishing appropriate timely treatment to return blood glucose to normal levels, reducing the risks of GDM-associated adverse pregnancy outcomes. ${ }^{43}$ Because of the widespread distribution of exosomes and the high stability of miRNAs, it may be possible to detect exosomes miRNA as a means to diagnosing early GDM in the future.

\section{Exosomal miRNAs and miRNAs as Potential Therapeutic Targets for GDM}

According to one study, increasingmiRNA-222 expression can inhibit the inflammatory response in GDM mice by promoting the expression of $\mathrm{C}-\mathrm{X}-\mathrm{C}$ chemokine receptor type 4 (CXCR4) and inactivating the nucleotide-binding oligomerization domain-like receptor family pyrin domain containing 3 (NLRP3) inflammasome. ${ }^{44}$ Additionally, upregulation of miR-351 prevents IR and liver gluconeogenesis in GDM mice by regulating flotillin 2 protein expression to inhibit the phosphatidylinositol 3-kinase/Akt protein kinase (PI3K/AKT) pathway. ${ }^{45}$ miRNA-221 can protect against GDM-induced islet dysfunction by targeting the p21-activated kinase (PAK1), which regulates of islet $\beta$-cells proliferation, apoptosis, and insulin secretion. ${ }^{46}$ Interestingly, naringin can downregulate the expression of miR-140-3p in trophoblasts and endothelial cells, thereby upregulating the expression of IR- $\alpha$ and insulin-like growth factor type 1 
receptor (IGF1R) and increasing trophoblast and endothelial cell glucose uptake. ${ }^{47}$ Lycium barbarum polysaccharide (LBP) could downregulate six miRNAs and reverse the rise in the expression of carnitine palmitoyltransferase 1a (CPT1A) protein to alleviate glucose intolerance, dyslipidemia and pathomorphological changes in liver histopathology of GDM mice fed a high-fat diet. ${ }^{48}$

There are many possible therapeutic targets and regimens (Figure 1). Currently, there is insufficient data for further animal experiments and clinical applications. It does, however, offer the possibility of treating GDM by adjusting patients' miRNA and exosomal miRNA. I hope it can be realized in the future through additional experimental research and later technical development.

\section{Conclusions and Prospects}

As the incidence of GDM rises, so will the number of maternal and fetal complications, with both short- and long-term adverse consequences. Therefore, early diagnosis and appropriate treatment of GDM are essential steps in preventing adverse pregnancy outcomes.

Several studies have characterized the expression of miRNAs and exosomal miRNAs in pregnant women's biological fluids and tissues, highlighting their role in mechanisms underlying the pathogenesis of GDM, such as IR and $\beta$-cell dysfunction. However, the potential molecular mechanisms are still not fully identified. In addition, identifying circulating biomarkers that may be effective in predicting GDM in the first trimester of pregnancy is essential to avoid maternal and fetal complications through timely lifestyle and dietary interventions. There is evidence that several circulating miRNAs and exosomal miRNAs have the potential to serve as early predictors of GDM. The main advantages of exosomal miRNAs as hypothetical biomarkers of GDM are significant exosome stability and simplified sample collection, particularly the use of peripheral blood samples. In contrast, other samples, such as amniotic fluid, are not easily collected. Early diagnosis and treatment of GDM by exosomal miRNAs appears to be highly promising in the future, but there is still a lack of sufficient experimental data and clinical application to support some existing theories. Moreover, research prospects should focus on the exploration of possible molecular mechanisms involved in the increased risk of the offspring to metabolic diseases in adulthood.

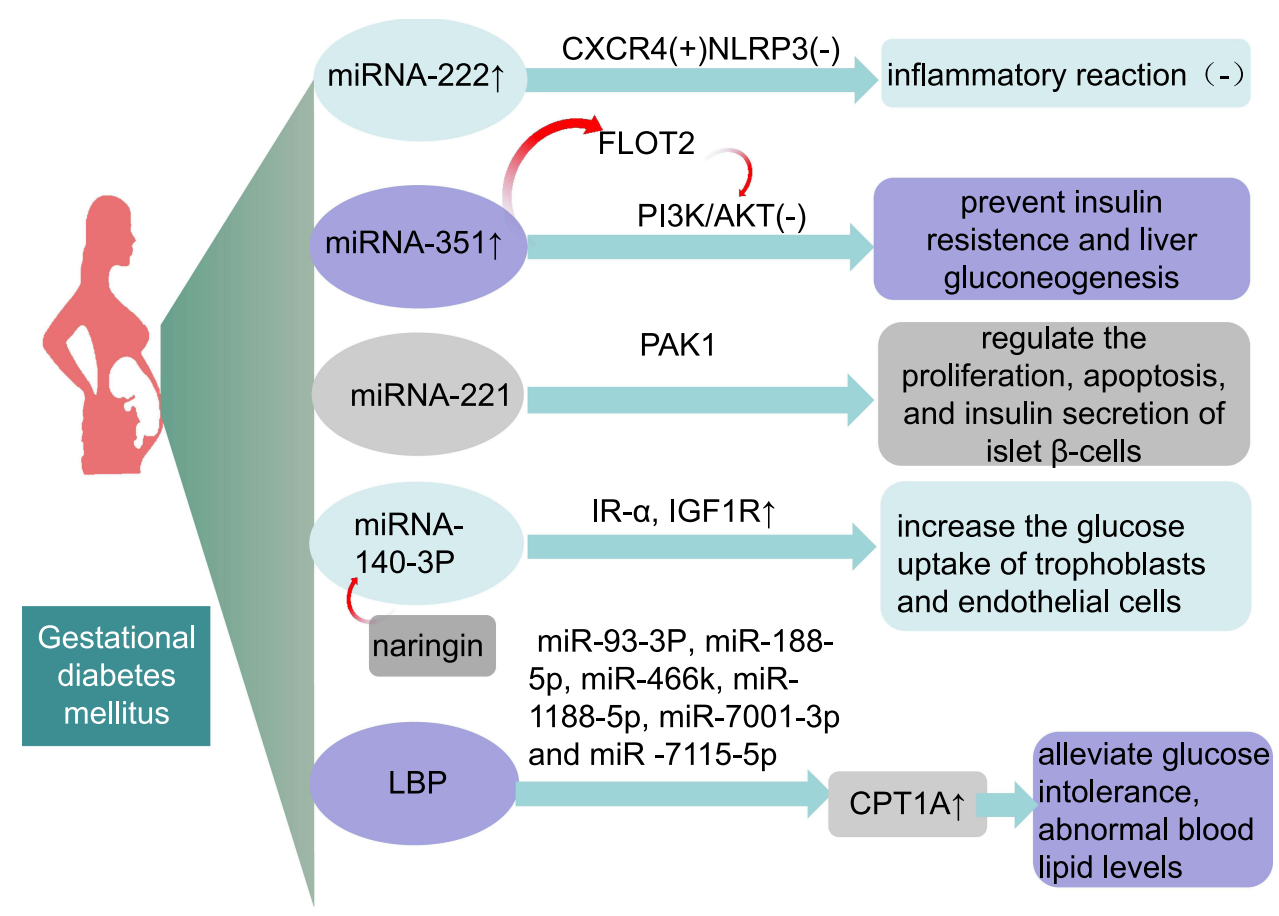

Figure I miRNAs and exosomal miRNAS may be potential therapeutic targets for GDM.

Abbreviations: miRNA, microRNA; CXCR4, recombinant chemokine C-X-C-motif receptor 4; NLRP3, NOD-like receptors family pyrin domain-containing 3; FLOT2, recombinant flotillin 2; LBP, Lycium barbarum polysaccharide. 


\section{Statement of Ethics}

This article does not contain any studies with human or animals performed by any of the authors.

\section{Consent for Publication}

Agreed to publish.

\section{Acknowledgments}

I wish to thank for the timely technical assistance and intellectual support given by Yujing He.

\section{Author Contributions}

Xiyao Yang collected the related papers and wrote the manuscript. $\mathrm{Na} \mathrm{Wu}$ provided direction and guidance throughout the preparation of this manuscript, and revise it critically for important intellectual content, and approved the final manuscript. All authors contributed to data analysis, drafting or revising the article, have agreed on the journal to which the article will be submitted, gave final approval of the version to be published, and agree to be accountable for all aspects of the work.

\section{Funding}

This research was supported by the National Natural Science Foundation of China (No.81700706), the 345 Talent Project of Shengjing hospital, the Clinical research project of Liaoning Diabetes Medical Nutrition Prevention Society (No. LNSTNBYXYYFZXH-RS01B), the Natural Science Foundation of Liaoning Province (No. 2021-MS-182), the Science Foundation of Liaoning Education Department (No. LK201603), and the Virtual simulation experiment teaching project of China Medical University (No.2020-47).

\section{Disclosure}

The authors declare no conflicts of interest in this work.

\section{References}

1. Caughey AB, Turrentine M. ACOG practice bulletin No. 190 Summary: gestational diabetes mellitus. Obstet Gynecol. 2018;131(2):406-408. doi:10.1097/aog.0000000000002498

2. Carracher AM, Marathe PH, Close KL. International diabetes federation 2017. J Diabetes. 2018;10(5):353-356. doi:10.1111/1753-0407.12644

3. Mirghani Dirar A, Doupis J. Gestational diabetes from A to Z. World J Diabetes. 2017;8(12):489-511. doi:10.4239/wjd.v8.i12.489

4. Saravanan P, Magee LA, Banerjee A. Gestational diabetes: opportunities for improving maternal and child health. Lancet Diabetes Endocrinol. 2020;8(9):793-800. doi:10.1016/s2213-8587(20)30161-3

5. O’Neill S, Bohl M, Gregersen S, Hermansen K, O’Driscoll L. Blood-based biomarkers for metabolic syndrome. Trends Endocrinol Metab. 2016;27 (6):363-374. doi:10.1016/j.tem.2016.03.012

6. Morales-Prieto DM, Favaro RR, Markert UR. Placental miRNAs in feto-maternal communication mediated by extracellular vesicles. Placenta. 2020;102:27-33. doi:10.1016/j.placenta.2020.07.001

7. Sebastiani G, Nigi L, Grieco GE, Mancarella F, Ventriglia G, Dotta F. Circulating microRNAs and diabetes mellitus: a novel tool for disease prediction, diagnosis, and staging? J Endocrinol Invest. 2017;40(6):591-610. doi:10.1007/s40618-017-0611-4

8. Salomon C, Rice GE. Role of exosomes in placental homeostasis and pregnancy disorders. Prog Mol Biol Transl Sci. 2017;145:163-179. doi:10.1016/bs.pmbts.2016.12.006

9. Sato-Kuwabara Y, Melo SA, Soares FA, Calin GA. The fusion of two worlds: non-coding RNAs and extracellular vesicles-diagnostic and therapeutic implications. Int J Oncol. 2015;46(1):17-27. doi:10.3892/ijo.2014.2712

10. Salomon C, Scholz-Romero K, Sarker S, et al. Gestational diabetes mellitus is associated with changes in the concentration and bioactivity of placenta-derived exosomes in maternal circulation across gestation. Diabetes. 2016;65(3):598-609. doi:10.2337/db15-0966

11. Nardi Fda S, Michelon TF, Neumann J, et al. High levels of circulating extracellular vesicles with altered expression and function during pregnancy. Immunobiology. 2016;221(7):753-760. doi:10.1016/j.imbio.2016.03.001

12. Guay C, Regazzi R. New emerging tasks for microRNAs in the control of $\beta$-cell activities. Biochim Biophys Acta. 2016;1861(12 Pt B):2121-2129. doi:10.1016/j.bbalip.2016.05.003

13. Li C, Qu L, Farragher C, Vella A, Zhou B. MicroRNA regulated macrophage activation in obesity. J Transl Int Med. 2019;7(2):46-52. doi:10.2478/ jtim-2019-0011

14. Plows JF, Stanley JL, Baker PN, Reynolds CM, Vickers MH. The pathophysiology of gestational diabetes mellitus. Int J Mol Sci. 2018;19 (11):3342. doi:10.3390/ijms19113342

15. McIntyre HD, Catalano P, Zhang C, Desoye G, Mathiesen ER, Damm P. Gestational diabetes mellitus. Nat Rev Dis Prim. $2019 ; 5(1): 47$. doi:10.1038/s41572-019-0098-8 
16. Zhou X, Xiang C, Zheng X. miR-132 serves as a diagnostic biomarker in gestational diabetes mellitus and its regulatory effect on trophoblast cell viability. Diagn Pathol. 2019;14(1):119. doi:10.1186/s13000-019-0899-9

17. Zhao C, Dong J, Jiang T, et al. Early second-trimester serum miRNA profiling predicts gestational diabetes mellitus. PLoS One. 2011;6(8):e23925. doi: 10.1371 /journal.pone. 0023925

18. Pheiffer C, Dias S, Rheeder P, Adam S. Decreased expression of circulating miR-20a-5p in South African women with gestational diabetes mellitus. Mol Diagn Ther. 2018;22(3):345-352. doi:10.1007/s40291-018-0325-0

19. Qi S, Wang X. Decreased expression of miR-185 in serum and placenta of patients with gestational diabetes mellitus. Clin Lab. 2019;65(12):Dec. doi:10.7754/Clin.Lab.2019.190445

20. Guan CY, Tian S, Cao JL, Wang XQ, Ma X, Xia HF. Down-regulated miR-21 in gestational diabetes mellitus placenta induces PPAR- $\alpha$ to inhibit cell proliferation and infiltration. Diabetes Metab Syndr Obes. 2020;13:3009-3034. doi:10.2147/dmso.s253920

21. Deng L, Huang Y, Li L, Chen H, Su J. Serum miR-29a/b expression in gestational diabetes mellitus and its influence on prognosis evaluation. J Int Med Res. 2020;48(9):300060520954763. doi:10.1177/0300060520954763

22. Fu S, Fu S, Ma X, Yang X, Ling J. miR-875-5p regulates IR and inflammation via targeting TXNRD1 in gestational diabetes rats. Mol Med Rep. 2021;23(5). doi:10.3892/mmr.2021.11942

23. Sebastiani G, Guarino E, Grieco GE, et al. Circulating microRNA (miRNA) expression profiling in plasma of patients with gestational diabetes mellitus reveals upregulation of miRNA miR-330-3p. Front Endocrinol (Lausanne). 2017;8:345. doi:10.3389/fendo.2017.00345

24. Wang J, Pan Y, Dai F, Wang F, Qiu H, Huang X. Serum miR-195-5p is upregulated in gestational diabetes mellitus. J Clin Lab Anal. 2020;34(8): e23325. doi:10.1002/jcla.23325

25. Dai S, Zhu X, Xia H. MiR-2467 is a potential marker for prediction of gestational diabetes mellitus in pregnancy. Clin Lab. 2020;66(10). doi:10.7754/Clin.Lab.2020.200233

26. Sørensen AE, van Poppel MNM, Desoye G, et al. The predictive value of miR-16, $-29 \mathrm{a}$ and -134 for early identification of gestational diabetes: a nested analysis of the DALI cohort. Cells. 2021;10(1):170. doi:10.3390/cells10010170

27. Liu L, Zhang J, Liu Y. MicroRNA-1323 serves as a biomarker in gestational diabetes mellitus and aggravates high glucose-induced inhibition of trophoblast cell viability by suppressing TP53INP1. Exp Ther Med. 2021;21(3):230. doi:10.3892/etm.2021.9661

28. Shen H, Sun J, Liu J, Wang L, Dong L. miR-181d promotes pancreatic beta cell dysfunction by targeting IRS2 in gestational diabetes mellitus. Ginekol Pol. 2021;92(8):563-570. doi:10.5603/GP.a2021.0077

29. Wen J, Bai X. miR-520h Inhibits cell survival by targeting mTOR in gestational diabetes mellitus. Acta Biochim Pol. 2021;68(1):65-70. doi:10.18388/abp.2020_5389

30. Wang F, Li Z, Zhao $\bar{M}$, et al. Circulating miRNAs miR-574-5p and miR-3135b are potential metabolic regulators for serum lipids and blood glucose in gestational diabetes mellitus. Gynecol Endocrinol. 2021;37(7):665-671. doi:10.1080/09513590.2021.1908990

31. Zheng T, Chen H. Resveratrol ameliorates the glucose uptake and lipid metabolism in gestational diabetes mellitus mice and insulin-resistant adipocytes via miR-23a-3p/NOV axis. Mol Immunol. 2021;137:163-173. doi:10.1016/j.molimm.2021.06.011

32. Martínez-Ibarra A, Martínez-Razo LD, Vázquez-Martínez ER, et al. Unhealthy levels of phthalates and bisphenol a in Mexican pregnant women with gestational diabetes and its association to altered expression of miRNAs involved with metabolic disease. Int J Mol Sci. 2019;20(13):3343. doi:10.3390/ijms20133343

33. Li HX, Li XH, Jiang J, Shi PX, Zhang XG, Tian M. Effect of miR-26b on gestational diabetes mellitus in rats via PI3K/Akt signaling pathway. Eur Rev Med Pharmacol Sci. 2020;24(4):1609-1615. doi:10.26355/eurrev_202002_20335

34. Gillet V, Ouellet A, Stepanov Y, et al. miRNA profiles in extracellular vesicles from serum early in pregnancies complicated by gestational diabetes mellitus. J Clin Endocrinol Metab. 2019;104(11):5157-5169. doi:10.1210/jc.2018-02693

35. Shah KB, Chernausek SD, Teague AM, Bard DE, Tryggestad JB. Maternal diabetes alters microRNA expression in fetal exosomes, human umbilical vein endothelial cells and placenta. Pediatr Res. 2021;89(5):1157-1163. doi:10.1038/s41390-020-1060-x

36. Zhang L, Zhang T, Sun D, et al. Diagnostic value of dysregulated microribonucleic acids in the placenta and circulating exosomes in gestational diabetes mellitus. $J$ Diabetes Investig. 2021;12(8):1490-1500. doi:10.1111/jdi.13493

37. Herrera-van Oostdam AS, Toro-Ortíz JC, López JA, et al. Placental exosomes isolated from urine of patients with gestational diabetes exhibit a differential profile expression of microRNAs across gestation. Int J Mol Med. 2020;46(2):546-560. doi:10.3892/ijmm.2020.4626

38. Nair S, Ormazabal V, Jayabalan N, et al. Circulating exosomal miRNA signature in gestational diabetes mellitus influences glucose metabolism in placental cells. Diabetes. 2018;67(Supplement1):164-LB. doi:10.2337/db18-164-LB

39. Zhang Z, Xu Q, Chen Y, et al. The possible role of visceral fat in early pregnancy as a predictor of gestational diabetes mellitus by regulating adipose-derived exosomes miRNA-148 family: protocol for a nested case-control study in a cohort study. BMC Pregnancy Childbirth. 2021;21 (1):262. doi:10.1186/s12884-021-03737-1

40. Jayabalan N, Scholz-Romero K, Guanzon D, et al. 1972-P: adipose tissue-derived exosomal microRNA regulates placental glucose uptake in gestational diabetes mellitus pregnancies. Diabetes. 2020;69(Supplement1):1972-P. doi:10.2337/db20-1972-P

41. American Diabetes Association. 2. Classification and diagnosis of diabetes. Diabetes Care. 2017;40(Supp11):S11-s24. doi:10.2337/dc17-S005

42. Rani PR, Begum J. Screening and diagnosis of gestational diabetes mellitus, where do we stand. J Clin Diagnostic Res. 2016;10(4):Qe01-4. doi: $10.7860 / \mathrm{jcdr} / 2016 / 17588.7689$

43. Sweeting A, Park F, Hyett J. The first trimester: prediction and prevention of the great obstetrical syndromes. Best Pract Res Clin Obstet Gynaecol. 2015;29(2):183-193. doi:10.1016/j.bpobgyn.2014.09.006

44. Zhang H, Luan S, Xiao X, Lin L, Zhao X, Liu X. Silenced microRNA-222 suppresses inflammatory response in gestational diabetes mellitus mice by promoting CXCR4. Life Sci. 2021;266:118850. doi:10.1016/j.1fs.2020.118850

45. Chen SH, Liu XN, Peng Y. MicroRNA-351 eases insulin resistance and liver gluconeogenesis via the PI3K/AKT pathway by inhibiting FLOT2 in mice of gestational diabetes mellitus. $J$ Cell Mol Med. 2019;23(9):5895-5906. doi:10.1111/jcmm.14079

46. Zhao H, Tao S. MiRNA-221 protects islet $\beta$ cell function in gestational diabetes mellitus by targeting PAK1. Biochem Biophys Res Commun. 2019;520(1):218-224. doi:10.1016/j.bbrc.2019.09.139

47. Zhao C, Zhao C, Zhao H. Defective insulin receptor signaling in patients with gestational diabetes is related to dysregulated miR-140 which can be improved by naringenin. Int J Biochem Cell Biol. 2020;128:105824. doi:10.1016/j.biocel.2020.105824 
48. Xiao Y, Chen W, Chen R, et al. Exosomal microRNA expression profiling analysis of the effects of Lycium barbarum polysaccharide on gestational diabetes mellitus mice. Evid Based Complement Alternat Med. 2020;2020:2953502. doi:10.1155/2020/2953502

\section{Publish your work in this journal}

Diabetes, Metabolic Syndrome and Obesity: Targets and Therapy is an international, peer-reviewed open-access journal committed to the rapid publication of the latest laboratory and clinical findings in the fields of diabetes, metabolic syndrome and obesity research. Original research, review, case reports, hypothesis formation, expert opinion and commentaries are all considered for publication. The manuscript management system is completely online and includes a very quick and fair peer-review system, which is all easy to use. Visit http://www.dovepress. com/testimonials.php to read real quotes from published authors.

Submit your manuscript here: https://www.dovepress.com/diabetes-metabolic-syndrome-and-obesity-targets-and-therapy-journal 